\title{
An Attempt to Explore the Various Challenges and Success Factors in Performing Arts Sector in India
}

\author{
Yogender Singh \\ Aryabhatt College, \\ University of Delhi \\ Delhi, India
}

\author{
Remica Aggarwal \\ Recventures Education \\ Services Private Limited, \\ Delhi, India
}

\author{
V. K. Aggarwal \\ Recventures Education \\ Services Private Limited
}

\author{
Lakshay Aggarwal \\ Recventures Education \\ Services Private Limited, \\ India
}

\begin{abstract}
Art \& Culture is India's strongest contribution to its rich heritage and history and is intrinsically woven into its identity. It contributes to India's GDP by generating both direct and indirect employment through handmade crafts and arts, unique only to our Country. There is another facet of art and culture which is getting recognised all over the world and that is performing arts ${ }^{1-2}$. Be it drama or stage or acts and plays, it is getting wide attention from the customers The customers being the hall listeners, or students or the scholars of the widely recognised universities. The potential in this sector is immense .With the help of multiple fascinating techniques such as use of crafts, colours ,acts, actions and acting, teachers are devising various ways to make it easy and interesting for the students to grasp the difficult and wieldy and even called scary concepts in education confidently and interestingly .Present paper explored the various challenges faced by performing arts particularly with education field or sector in India . Thereafter it also proposed the interrelationship amongst them using ISM methodology.
\end{abstract}

\section{Keywords}

Teachers, drama, fine arts, stage shows, performing arts, ISM Methodology, MIC -Mac Analysis , Budding talents

\section{INTRODUCTION}

In the era of smartphones and the internet, everything is changing so fast. The need for progression has become inevitable in every aspect of human life. Businesses are getting inclusive, technology is becoming more convenient and communication has become lightning fast. When all other sectors are growing at this pace, how can education sector lag behind? From traditional to smart learning, education has gone through enormous changes. But in the epoch of smart classes, traditional ways of imparting education are still relevant and quite productive.

There is another aspect associated with drama and arts also collectively or popularly known as performing arts. This is recently getting recognized in developing countries such as India in recent times. Though it is quite popular in various countries such as U.K , USA etc., in India, it is new and getting whole heartedly recognized.

Spoon-feeding a chunk of information and students gulping it down without reason can be disastrous for the society. To stimulate creativity, smart learning, critical thinking and logical reasoning in students, the drama and arts play a pivotal role in the education process. If in a controlled atmosphere, a group of students are asked to replicate a historic scene, students find it easy to remember and understand without having to cram a bunch of names and dates from History. Drama and Arts a.k.a performing arts in education have been inculcated as part of the curriculum at many institutions around the world to promote effective learning. Be it through puppetry or role-play, students learn the interpersonal and group communication, and public speaking skills and also the method helps to foster knack for exploration in them.

\subsection{Theatre in Education}

- Storytelling is a powerful tool to facilitate learning in a meaningful manner. Since theatre itself is a potential driver of bringing impactful change in society, it can play a crucial role in utilising drama and art in education.

- Using theatrical musicals as well as dramas, learning can be carried out in an interesting manner. It caters to different learning methods as it adheres to VARK, which is a famed teaching model by Neil Fleming and emphasises on the use of Visual, Aural, Read/Write and Kinesthetic Sensory in education. Through creative stories and theatre dramas, a multi-sensory experience can be curated thus making learning a fun and engaging process.

\subsection{Drama in Education}

The element of Drama used in the process of education may vary for institutions depending on the approach they use and the goal they aspire to achieve. The common form of Drama implemented in the process of imparting education is a 'Role Play'. A role play involves a group of students in a controlled atmosphere where they replicate a scene from history or from a play or a movie. The students are given the roles of the characters of the event. They not only learn to understand the mentality of the characters but also learn behavioural psychology, based on which they make critical judgements.

In order to immerse the students in the scene and to understand its essence, use of costumes and sets is made. This activity proves to be very useful in making them better thinkers and storytellers and infuse in them the confidence to engage with others in healthy interactions. For future filmmakers and dramatists, this activity turns out to be the cornerstone of their career. Other than role play for utilising drama and art in education, there are co-curricular activities to engage children and carving out a better learning experience. The popular amongst them could be mime exercises, creating literary sketches; Charades; writing a story from the favourite drama's characters; One-word story etc.; critical thinking approaches.

\subsection{Implementing Art in Learning}

Making use of art forms is the best way to attract young students to learning. It is hard for a teacher to tell a student in kindergarten about the benefits of education. The graphical representation of texts, assigning a picture to an object and to 
tell a story through motion graphics or toys has proven to be effective in exposing the young students to educational journey. Some of the prominent activities you can practice with children to help them learn better are:

- $\quad$ Painting \& Drawing

- Using visuals to learn something

- Transforming complicated concepts into rhymes and songs

- Using puppets to explain a concept

- Creating stories from a single word

The present research focuses on exploring various types of challenges which are faced by implementing performing arts in the education sector primarily and that too in developing countries. Section 2 depict such challenges . Thereafter, section 3 describes the ISM methodology. case example is presented in section 4. Managerial implications have been presented in section 5 .

\section{LITERATURE REVIEW ON SUCCESS FACTORS BEHIND WIDESPREAD USE OF PERFORMING ARTS IN EDUCATION 1,2}

\section{1 e- learning environment (e-LE):}

e-learning promoted with the help of videos on online platforms helps learners and students who cannot attend the classrooms. They can take benefits of live classrooms .

\subsection{Recognisable cost investments (RCI):} such kind of art requires funds and often project experience cost overruns . Recognisable amount of financial investments helps.

\subsection{Increased participation / mutual} teacher -student participation [TSP]:If a teacher dares to indulge herself in roles and be involved in drama education, the children will want to participate Toivanen [1],[11] emphasizes that pedagogical courage, or daring to take risks is at least as important to the drama lesson as the teaching skills. When the teacher is ready to put her/himself on the line, the students become excited about the drama and work more boldly and with greater enthusiasm.

\subsection{Appropriate management of time [} AMT] :The success of the lesson means that they participate in drama action. Teachers who use drama in education need to be able to manage time, space and bodies in an open classroom and to do so in both the social dimension of the classroom and in the aesthetic dimension of the art form.

\subsection{Recognition and felicitation [ R\&F]:}

There has to be recognition and felicitation. Teachers' work in drama education dual reality is challenging specially at the beginning [2]. According to $[3,4,5]$, teachers' pedagogical thinking is connected to a teaching-studying-learning process in the natural context of the classroom.

\subsection{Well experienced teachers [ WET] :}

When the teacher has more experience in teaching drama, she or he is able to make decisions that contribute to the success of an hour. Limited experience in teaching drama, in turn, leads to the experience of failure because the teacher does not know how students should act in the drama lesson $[6,1,10]$. A teacher's enthusiasm transmitted to pupils and motivates them to work drama. Teachers highlighted the need for courage and confidence in drama teaching.

2.7 Group structural factors [GSF]:[8,9,10] have explained that group structural factors consist of the interaction between the different roles and norms. In addition, group size is included in the category group structural factors in this study because the size of the group affects the interaction between the students and the teacher. According to teachers, a good and trusting atmosphere in a classroom will increase the success of drama lessons.

\subsection{Replication in controlled atmosphere} [RCA][11] ${ }^{1,2}$ :If in a controlled atmosphere, a group of students are asked to replicate a historic scene, students find it easy to remember and understand without having to cram a bunch of names and dates from History. Drama and Arts in education have been inculcated as part of the curriculum at many institutions around the world to promote effective learning.

\subsection{Pre-interactive and interactive teaching} skills [ITS] : Mother tongue is defined as an informational, skill and artistic subject, which is divided into three subareas: reading and writing, literature, and language and interaction skills. Drama objectives and core contents are included under the sub-heading of interaction skills. The interaction section involves the teaching of linguistic and physical expression skills.

2.10 Flexible planning [FP]: According to teachers, the planning of the drama lesson leads to the success of drama lessons. The planning supports especially inexperienced teachers. However, planning must be flexible, because anything can happen during a drama lesson. If the teacher plans too strictly or does not plan at all, it is likely that the drama lesson will fail.

\subsection{Motivation towards critical thinking} and Pedagogical thinking [MCT/ PT] : According to $[3,4,5]$, teachers' pedagogical thinking is connected to a teaching-studying-learning process in the natural context of the classroom. Pedagogical thinking is characterized by setting learning objectives and having reasons for making pedagogical decisions.

\subsection{An authentic and expressive} performance $(\mathbf{A} \& \mathbf{E P})$ : $T$ his includes the performance both by teachers which motivates the students also to perform better. [12]

2.13 Family support and sacrifices [FSS] : This could be in terms of schedules and job adjustments on part of parents to ensure their child actively participates [9]. Many personal and financial sacrifices had to be made, not just on the part of parents, but by siblings. At times, family sacrifice extended beyond the parents to the extended family, siblings and friends. In addition to the emotional support, parents made adjustments in their schedules and some changed jobs to enable their children to participate in the arts program. In some cases these were major sacrifices. 


\subsection{Knowledge learning from role models}

(KRM): Knowledge about popular figures in the field helps.

\section{ISM METHODOLOGY}

Interpretive structural modelling methodology or ISM [13] is a known technique to map the relationships amongst the relevant elements as per decision maker's problems in a hierarchical manner. Starting with the identification of elements, it proceeds with establishing the contextual relationships between elements (by examining them in pairs ) and move on towards developing the structural selfinteraction (SSIM) matrix using VAXO [13] and then initial reachability matrix and final reachability matrix and rearranging the elements in topological order using the level partition matrices. A Mic-Mac analysis is performed afterwards which categorize the variables as per the driving and dependence power in to autonomous, dependent, driver and linkage category. Finally, a diagraph can be obtained.

\section{CASE PROBLEM}

Around 14 success factors have been identified which are normally helpful and beneficial while teaching through performing arts.

\subsection{Construction of Structural Self - Interaction Matrix (SSIM)}

This matrix gives the pair-wise relationship between two variables i.e. $i$ and $j$ based on VAXO. SSIM has been presented below in Fig 1.

\subsection{Construction of Initial Reachability \\ Matrix and final reachability matrix}

The SSIM has been converted in to a binary matrix called the initial reachability matrix shown in fig. 2 by substituting V, A, $\mathrm{X}, \mathrm{O}$ by 1 or 0 as per the case. After incorporating the transitivity, the final reachability matrix is shown below in the Fig 3.

Fig 1: SSIM matrix for pair wise relationship amongst barriers

\begin{tabular}{|c|c|c|c|c|c|c|c|c|c|c|c|c|c|c|c|}
\hline $\begin{array}{c}\text { S. } \\
\text { No. }\end{array}$ & Barriers & 1 & 2 & 3 & 4 & 5 & 6 & 7 & 8 & 9 & 10 & 11 & 12 & 13 & 14 \\
\hline 1 & e-LE & & A & X & X & V & X & V & V & V & X & V & V & A & V \\
\hline 2 & RCI & & X & A & V & X & X & V & O & V & V & V & A & V \\
\hline 3 & TSP & & & & V & V & X & V & V & V & V & V & V & A & V \\
\hline 4 & AMT & & & & V & A & A & V & O & V & V & V & A & V \\
\hline 5 & R\&F & & & & & A & A & V & A & V & V & V & A & V \\
\hline 6 & WET & & & & & & V & V & X & V & V & V & A & V \\
\hline 7 & GSF & & & & & & & V & V & V & V & V & A & V \\
\hline 8 & RCA & & & & & & & & A & V & V & V & A & V \\
\hline 9 & ITS & & & & & & & & & V & A & V & A & O \\
\hline 10 & FP & & & & & & & & & & & A & V & A & A \\
\hline 11 & MCT/PT & & & & & & & & & & & V & A & A \\
\hline 12 & A\&EP & & & & & & & & & & & & A & V \\
\hline 13 & FSS & & & & & & & & & & & & & V \\
\hline 14 & KRM & & & & & & & & & & & & & \\
\hline
\end{tabular}

Fig 2: Initial reachability matrix

\begin{tabular}{|c|c|c|c|c|c|c|c|c|c|c|c|c|c|c|c|}
\hline $\begin{array}{c}\text { S. } \\
\text { No. }\end{array}$ & Barriers & 1 & 2 & 3 & 4 & 5 & 6 & 7 & 8 & 9 & 10 & 11 & 12 & 13 & 14 \\
\hline & & $\begin{array}{c}\text { e- } \\
\text { LE }\end{array}$ & RCI & TSP & AMT & R\&F & WET & GSF & RCA & ITS & FP & $\begin{array}{c}\text { MCT } \\
/ \text { PT }\end{array}$ & A\&EP & FSS & KRM \\
\hline 1 & e-LE & 1 & 0 & 1 & 1 & 1 & 1 & 1 & 1 & 1 & 1 & 1 & 1 & 0 & 1 \\
\hline 2 & RCI & 1 & 1 & 1 & 0 & 1 & 1 & 1 & 1 & 0 & 1 & 1 & 1 & 0 & 1 \\
\hline 3 & TSP & 1 & 1 & 1 & 1 & 1 & 1 & 1 & 1 & 1 & 1 & 1 & 1 & 0 & 1 \\
\hline 4 & AMT & 1 & 1 & 0 & 1 & 1 & 0 & 0 & 1 & 0 & 1 & 1 & 1 & 0 & 1 \\
\hline 5 & R\&F & 0 & 0 & 0 & 0 & 1 & 0 & 0 & 1 & 0 & 1 & 1 & 1 & 0 & 1 \\
\hline
\end{tabular}




\begin{tabular}{|c|c|c|c|c|c|c|c|c|c|c|c|c|c|c|c|}
\hline 6 & WET & 1 & 1 & 1 & 1 & 1 & 1 & 1 & 1 & 1 & 1 & 1 & 1 & 0 & 1 \\
\hline 7 & GSF & 0 & 1 & 0 & 1 & 1 & 0 & 1 & 1 & 1 & 1 & 1 & 1 & 0 & 1 \\
\hline 8 & RCA & 0 & 0 & 0 & 0 & 0 & 0 & 0 & 1 & 0 & 1 & 1 & 1 & 0 & 1 \\
\hline 9 & ITS & 0 & 0 & 0 & 0 & 1 & 1 & 0 & 1 & 1 & 1 & 0 & 1 & 0 & 0 \\
\hline 10 & FP & 1 & 0 & 0 & 0 & 0 & 0 & 0 & 0 & 0 & 1 & 0 & 1 & 0 & 0 \\
\hline 11 & MCT/PT & 0 & 0 & 0 & 0 & 0 & 0 & 0 & 0 & 1 & 1 & 1 & 1 & 0 & 0 \\
\hline 12 & A\&EP & 0 & 0 & 0 & 0 & 0 & 0 & 0 & 0 & 0 & 0 & 0 & 1 & 0 \\
\hline 13 & FSS & 1 & 1 & 1 & 1 & 1 & 1 & 1 & 1 & 1 & 1 & 1 & 1 & 1 \\
\hline 14 & KRM & 0 & 0 & 0 & 0 & 0 & 0 & 0 & 0 & 0 & 1 & 1 & 0 \\
\hline
\end{tabular}

Fig 3 : Final reachability matrix

\begin{tabular}{|c|c|c|c|c|c|c|c|c|c|c|c|c|c|c|c|c|}
\hline $\begin{array}{l}\text { S. } \\
\text { No. }\end{array}$ & Barriers & 1 & 2 & 3 & 4 & 5 & 6 & 7 & 8 & 9 & 10 & 11 & 12 & 13 & 14 & D.P \\
\hline & & $\begin{array}{l}\text { e- } \\
\text { LE }\end{array}$ & RCI & TSP & AMT & $R \& F$ & WET & GSF & RCA & ITS & FP & $\begin{array}{c}\mathrm{MCT} \\
/ \mathrm{PT}\end{array}$ & A\&EP & FSS & KRM & \\
\hline 1 & e-LE & 1 & 1 & 1 & 1 & 1 & 1 & 1 & 1 & 1 & 1 & 1 & 1 & 0 & 1 & 13 \\
\hline 2 & RCI & 1 & 1 & 1 & 1 & 1 & 1 & 1 & 1 & 1 & 1 & 1 & 1 & 0 & 1 & 13 \\
\hline 3 & TSP & 1 & 1 & 1 & 1 & 1 & 1 & 1 & 1 & 1 & 1 & 1 & 1 & 0 & 1 & 13 \\
\hline 4 & AMT & 1 & 1 & 1 & 1 & 1 & 1 & 1 & 1 & 0 & 1 & 1 & 1 & 0 & 1 & 12 \\
\hline 5 & $\mathrm{R} \& \mathrm{~F}$ & 1 & 0 & 0 & 0 & 1 & 0 & 0 & 1 & 0 & 1 & 1 & 1 & 0 & 1 & 7 \\
\hline 6 & WET & 1 & 1 & 1 & 1 & 1 & 1 & 1 & 1 & 1 & 1 & 1 & 1 & 0 & 1 & 13 \\
\hline 7 & GSF & 1 & 1 & 1 & 1 & 1 & 1 & 1 & 1 & 1 & 1 & 1 & 1 & 0 & 1 & 13 \\
\hline 8 & RCA & 1 & 0 & 0 & 0 & 0 & 0 & 0 & 1 & 0 & 1 & 1 & 1 & 0 & 1 & 6 \\
\hline 9 & ITS & 0 & 0 & 0 & 0 & 1 & 1 & 0 & 1 & 1 & 1 & 1 & 1 & 0 & 1 & 8 \\
\hline 10 & FP & 1 & 0 & 1 & 1 & 1 & 1 & 1 & 1 & 1 & 1 & 1 & 1 & 0 & 1 & 12 \\
\hline 11 & $\mathrm{MCT} / \mathrm{PT}$ & 1 & 0 & 0 & 0 & 1 & 1 & 0 & 1 & 1 & 1 & 1 & 1 & 0 & 0 & 8 \\
\hline 12 & A\&EP & 0 & 0 & 0 & 0 & 0 & 0 & 0 & 0 & 0 & 1 & 1 & 1 & 0 & 1 & 4 \\
\hline 13 & FSS & 1 & 1 & 1 & 1 & 1 & 1 & 1 & 1 & 1 & 1 & 1 & 1 & 1 & 1 & 14 \\
\hline 14 & KRM & 1 & 0 & 0 & 0 & 0 & 0 & 0 & 0 & 1 & 1 & 1 & 1 & 0 & 1 & 6 \\
\hline & De.P & 12 & 7 & 8 & 8 & 11 & 10 & 8 & 12 & 10 & 14 & 14 & 14 & 1 & 13 & \\
\hline
\end{tabular}

D.P : Driving power ; De.P : dependence power

\subsection{Level Partition}

From the final reachability matrix, reachability and final antecedent set for each factor are found. The element for which the reachability and intersection sets are same are the top-level element in the ISM hierarchy. After the identification of top level element, it is separated out from the other elements and the process continues for next level of elements. Iterations have been shown from table $1-$ table 7 below .

Table 1 Iteration I

\begin{tabular}{|c|c|c|c|c|}
\hline $\begin{array}{c}\text { S. } \\
\text { No } \\
\cdot\end{array}$ & Reachability set & Antecedent set & $\begin{array}{c}\text { Intersect } \\
\text { ion set }\end{array}$ & $\begin{array}{c}\text { Le } \\
\text { vel }\end{array}$ \\
\hline
\end{tabular}

\begin{tabular}{|c|c|c|c|}
\hline 1 & $10,11,12$ & $\begin{array}{l}1,2,3,4,5,6,7,8,9 \\
10,11,12,13,14\end{array}$ & $10,11,12$ \\
\hline 2 & $\begin{array}{c}10,11,12, \\
14\end{array}$ & $\begin{array}{c}1,2,3,4,5,6,7,8,9 \\
, 10,12,13,14\end{array}$ & $10,12,14$ \\
\hline 3 & $1,8,10,11,12,14$ & $\begin{array}{c}1,2,3,4,5,6,7,8,9 \\
, 10,13\end{array}$ & $1,8,10$ \\
\hline 4 & $\begin{array}{c}1,5,8,10,11,12,1 \\
4\end{array}$ & $\begin{array}{c}1,2,3,4,5,6,7,9,1 \\
0,13\end{array}$ & $1,5,10$ \\
\hline 5 & $\begin{array}{c}1,5,6,8,10, \\
11,12,14\end{array}$ & $\begin{array}{c}1,2,3,4,6,7,9,10, \\
13\end{array}$ & $1,6,10$ \\
\hline 6 & $1,3,4,5,6,7,8,10$ & $1,2,3,4,6,7,10$ & $1,3,4,6,7$ \\
\hline
\end{tabular}




\begin{tabular}{|c|c|c|c|}
\hline & $11,12,14$ & 13 & 10 \\
\hline 7 & $\begin{array}{c}1,2,3,4,5,6,7,8 \\
10,11,12,14\end{array}$ & $\begin{array}{c}1,2,3,4,6,7,10, \\
13\end{array}$ & $\begin{array}{c}1,2,3,4,6 \\
7,10\end{array}$ \\
\hline 8 & $\begin{array}{c}1,2,3,4,5,6,7,8,1 \\
0,11,12,13,14\end{array}$ & $\begin{array}{c}1,2,3,4,6,7,10 \\
13\end{array}$ & $\begin{array}{c}1,2,3,4,6, \\
7,10,13\end{array}$ \\
\hline
\end{tabular}

Table 2 Iteration II

\begin{tabular}{|c|c|c|c|c|}
\hline $\begin{array}{l}\text { S. } \\
\text { N } \\
\text { o. }\end{array}$ & $\begin{array}{c}\text { Reachability } \\
\text { set }\end{array}$ & Antecedent set & $\begin{array}{c}\text { Intersect } \\
\text { ion set }\end{array}$ & $\begin{array}{c}\text { Lev } \\
\text { el }\end{array}$ \\
\hline 2 & 14 & $\begin{array}{c}1,2,3,4,5,6,7,8,9 \\
13,14\end{array}$ & 14 & \\
\hline 3 & $1,8,14$ & $\begin{array}{c}1,2,3,4,5,6,7,8,9 \\
13\end{array}$ & 1,8 & \\
\hline 4 & $1,5,8,14$ & $\begin{array}{c}1,2,3,4,5,6,7,9 \\
13\end{array}$ & 1,5 & II \\
\hline 5 & $1,5,6,8,14$ & $1,2,3,4,6,7,9,13$ & 1,6 & \\
\hline 6 & $1,3,4,5,6,7,8,14$ & $1,2,3,4,6,7,13$ & $1,3,4,6,7$ & \\
\hline 7 & $\begin{array}{c}1,2,3,4,5,6,7,8 \\
14\end{array}$ & $1,2,3,4,6,7,13$ & $1,2,3,4,7$ & \\
\hline 8 & $\begin{array}{c}1,2,3,4,5,6,7,8 \\
13,14\end{array}$ & $1,2,3,4,6,7,13$ & $\begin{array}{c}1,2,3,4,7 \\
13\end{array}$ & \\
\hline
\end{tabular}

Table Iteration III

\begin{tabular}{|c|c|c|c|c|}
\hline $\begin{array}{c}\text { S.N } \\
\text { o. }\end{array}$ & $\begin{array}{c}\text { Reachability } \\
\text { set }\end{array}$ & Antecedent set & $\begin{array}{c}\text { Intersecti } \\
\text { on set }\end{array}$ & $\begin{array}{c}\text { Lev } \\
\text { el }\end{array}$ \\
\hline 3 & $\mathbf{1 , 8}$ & $\begin{array}{c}1,2,3,4,5,6,7,8, \\
9,13\end{array}$ & $\mathbf{1 , 8}$ & \\
\cline { 1 - 4 } & $1,5,8$ & $\begin{array}{c}1,2,3,4,5,6,7,9, \\
13\end{array}$ & 1,5 & \multirow{2}{*}{ III } \\
\hline 5 & $1,5,6,8$ & $\begin{array}{c}1,2,3,4,6,7,9, \\
13\end{array}$ & 1,6 & \\
\cline { 1 - 4 } & & $1,2,3,4,6,7,13$ & $1,3,4,6,7$, & \\
\cline { 1 - 4 } & $1,3,4,5,6,7,8$ & $1,2,3,4,6,7,13$ & $1,2,3,4,7$ & \\
\hline 8 & $1,2,3,4,5,6,7,8$ & $1,2,3,4,6,7,13$ & $1,2,3,4,7$, & \\
&, 13 & & 13 & \\
\hline
\end{tabular}

Table 4 Iteration IV

\begin{tabular}{|c|c|c|c|}
\hline $\begin{array}{c}\text { S.No } \\
\text {. }\end{array}$ & $\begin{array}{c}\text { Reachability } \\
\text { set }\end{array}$ & $\begin{array}{c}\text { Antecedent } \\
\text { set }\end{array}$ & $\begin{array}{c}\text { Intersectio } \\
\text { n set }\end{array}$ \\
\hline 4 & 5 & $\begin{array}{c}2,3,4,5,6,7,9 \\
, 13\end{array}$ & 5 \\
\hline 5 & 5,6 & $\begin{array}{c}2,3,4,6,7,9 \\
13\end{array}$ & 6 \\
\hline 6 & $3,4,5,6,7$ & $2,3,4,6,7,13$ & $3,4,6,7$ \\
\hline 7 & $2,3,4,5,6,7$ & $2,3,4,6,7,13$ & $2,3,4,7,10$ \\
\hline 8 & $2,3,4,5,6,7,1$ & $2,3,4,6,7,13$ & $2,3,4,7,13$ \\
\hline
\end{tabular}

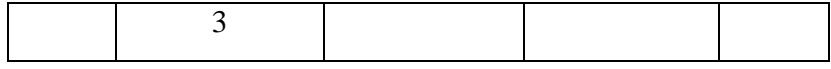

Table 5 Iteration V

\begin{tabular}{|c|c|c|c|c|}
\hline S.No. & $\begin{array}{c}\text { Reachability } \\
\text { set }\end{array}$ & $\begin{array}{c}\text { Antecedent } \\
\text { set }\end{array}$ & $\begin{array}{c}\text { Intersection } \\
\text { set }\end{array}$ & Level \\
\hline 5 & $\mathbf{6}$ & $\begin{array}{c}2,3,4,6,7,9, \\
13\end{array}$ & 6 & \multirow{2}{*}{ V } \\
\cline { 1 - 4 } 6 & $3,4,6,7$ & $\begin{array}{c}2,3,4,6,7, \\
13\end{array}$ & $3,4,6,7$ & \\
\hline 7 & $2,3,4,6,7$ & $\begin{array}{c}2,3,4,6,7, \\
13\end{array}$ & $2,3,4,7,10$ & \\
& & & \\
\hline 8 & $2,3,4,6,7,13$ & $2,3,4,6,7$, & $2,3,4,7,13$ & \\
& & 13 & & \\
\hline
\end{tabular}

Table 6 Iteration VI

\begin{tabular}{|c|c|c|c|c|}
\hline S.No. & $\begin{array}{c}\text { Reachability } \\
\text { set }\end{array}$ & $\begin{array}{c}\text { Antecedent } \\
\text { set }\end{array}$ & $\begin{array}{c}\text { Intersection } \\
\text { set }\end{array}$ & Level \\
\cline { 1 - 3 } 6 & $\mathbf{3 , 4 , 7}$ & $2,3,4,7,13$ & $\mathbf{3 , 4 , 7}$ & \multirow{2}{*}{ VI } \\
\cline { 1 - 4 } 7 & $2,3,4,7$ & $2,3,4,7,13$ & $2,3,4,7$ & \\
\cline { 1 - 4 } 8 & $2,3,4,7,13$ & $2,3,4,7,13$ & $2,3,4,7,13$ & \\
\hline
\end{tabular}

Table 7 Iteration VII

\begin{tabular}{|c|c|c|c|c|}
\hline $\begin{array}{c}\text { S. } \\
\text { No }\end{array}$ & $\begin{array}{c}\text { Reachability } \\
\text { set }\end{array}$ & $\begin{array}{c}\text { Antecedent } \\
\text { set }\end{array}$ & $\begin{array}{c}\text { Intersection } \\
\text { set }\end{array}$ & Level \\
\hline 7 & $\mathbf{2}$ & 2,13 & 2 & VII \\
\hline 8 & $\mathbf{2 , 1 3}$ & 2,13 & 2,13 & \\
\hline
\end{tabular}

\subsection{Driving power - dependence diagram}

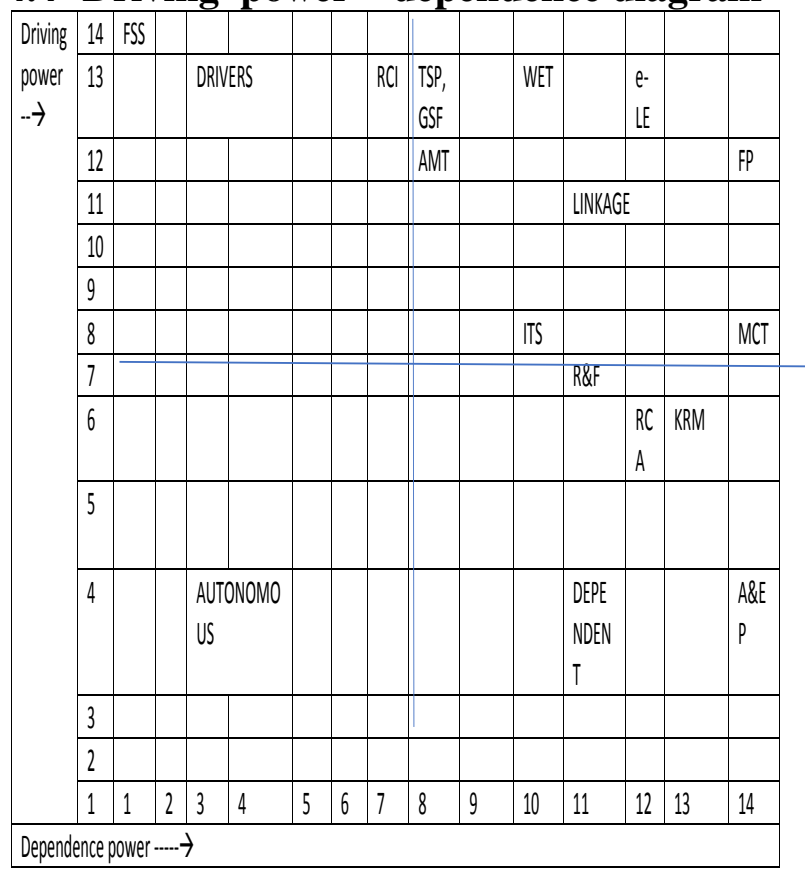

Fig 4 : Driving power and dependence diagram 


\section{CONCLUSIONS}

The present paper highlights some of the success factors behind the successful implementation of performing arts in education. Thereafter it examines the inter-relationships amongst them using ISM Methodology.

\section{ACKNOWLEDGMENTS}

Author Remica Aggarwal extend her warm regards to the faculties and students involved in performing arts in education field for the motivation to write this piece of research.

\section{APPENDIX}

A1: BENEFITS OF STUDYING PERFORMING ARTS

A better curriculum framework to offer as a 21 st century focus that highlights the transferable skills the STEM lobby champion is the Four Cs:

1. Critical Reflection : The arts provide a place of solitude, where students can immerse themselves without interference from their environment. This also provides a space for students to engage in selfreflection - a vital skill for life after school.

2. Collaboration: Students have the opportunity to engage in creative collaboration, a skill they have limited chance to develop outside of a rehearsal space.

3. Creativity There is also great cross-over between performing arts and other disciplines - the creative thinking and study techniques learned during rehearsal can be transferred to all areas of study.

4. Communication: Communication skills can be accelerated through performing arts, as students learn to use verbal and non-verbal techniques in new ways to deliver their message. Some students also find new levels of confidence through performing arts.

\section{REFERENCES}

[1] Toivanen,T., Pyykkö, A \& Ruismäki, H. 2011. Challenge of the empty space. Group factors as a part of drama education. Procedia: Social and Behavioral Sciences, 29, 402-411.

[2] Toivanen, T. \& Rantala, H. \& Ruismäki, H. 2009. Young primary school teachers as drama educators - possibilites and challanges. In H. Ruismäki \& I. Ruokonen (Eds.) Arts-Contact Points Between Cultures. 1st International Journal of Intercultural Arts Education Conference: PostConference Book (pp.129-140). University of Helsinki.
Research Report 312. Helsiki: University Press.

[3] Kansanen P.1999. Teaching as teaching-studyinglearning interaction. Scandinavian journal of Education Research, 43(1), 81-89.

[4] Tirri, K. (2012). The Core of School Pedagogy: Finnish Teacher's Views on the Educational Purposefulness of Their Teaching. In H. Niemi, A. Toom \& A. Kallioniemi (Eds.), Miracle of Education. The Principles and Practices of Teaching and Learning in Finnish Schools (pp.55-68). Rotterdam: Sence Publishers. ervention research as teacher professional development. Research in Drama Education: The Journal of Applied Theatre and Performance, 14(2), 225 - 243.

[5] Jyrhämä, R. \& Maaranen K. 2012. Research Orientation in a Teacher's Work. In H. Niemi, A. Toom, \& A Kallioniemi (Eds.), Miracle of Education. The Principles and Practices of Teaching and Learning in Finnish Schools. (pp.97-111). Rotterdam: Science Publishers.

[6] Saebø, A. B. 2009. Challenges and possibilities in Norwegian classroom drama practise. Research in Drama Education, The Journal of Applied Theatre and Performance. 14(2), 279- 294.

[7] Johnson, D. W., \& Johnson, F.P. 2009. Joining together: Group theory and group skills. Upper Saddle River, N.J: Pearson Education.

[8] Bloom, B. (Ed.). (1985). Developing talent in young people. New York: Ballantine Books.

[9] Tapio, T., Liisa , A. „Heikki, R. 2012 . Teachers perceptions of factors determining the success or failure of drama lessons . Procedia - Social and Behavioral Sciences $45,555-565$.

[10] Toivanen,T., Pyykkö, A \& Ruismäki, H. (2011). Challenge of the empty space. Group factors as a part of drama education. Procedia: Social and Behavioral Sciences. 29, 2011, 402 -411.

[11] Sawyer, K. 2004. Creative Teaching: Collaborative Discussionas Disciplined Improvisation. Educational Researcher, 33(2), 12-20.

[12] Wales, P. 2009. Positioning the drama teacher: Exploring the power of identity in teaching practices. Research in Drama Education, The Journal of Applied Theatre and Performance. 14(2), $261-278$.

[13] Warfield, J. N. 1974. Developing interconnection matrices in structural modeling. IEEE Transactions on System, Man, and Cybernetics, SMC-4 (1), 81-87. 